\title{
CRIAÇÕES E TRANSGRESSÕES NO DIÁLOGO ENTRE TRANSGENERIDADE E DEFICIÊNCIA: “ENTRE TRAVAS E RODAS”
}

\author{
Giovanna Marafon ${ }^{1}$ \\ https://orcid.org/0000-0003-3423-4676 \\ Roberta Piluso ${ }^{2}$ \\ https://orcid.org/0000-0002-3758-3663
}

Resumo: Neste artigo propomos realizar a descrição de seis episódios criados para o canal do Youtube "Entre travas e rodas", em que uma mulher cadeirante (Ivone Gomes conhecida como "gata de rodas") e uma mulher travesti (Amara Moira) se encontram e articulam suas pautas e discussões em comum, tais como: as dificuldades de transitar pela cidade, os olhares de estranhamento e a capacidade compulsória, abordando ainda questões relativas a sexualidades, transexualidade, representatividade, acessibilidade e capacitismo. A partir desse importante material audiovisual de acesso amplo e gratuito, realizamos uma análise sobre as relações entre os estudos de gênero e os estudos da deficiência, interrogando como ambos se articulam e como cada campo contribui para o outro, problematizando a transversalidade entre os estudos de gênero e os estudos da deficiência para afirmar corpos transgressores. Para isso, assumimos a perspectiva do Modelo Social da Deficiência, com uma leitura feminista pautada na abordagem interseccional, com influência das teorias queer e crip. A discussão percorrerá ainda o referencial teórico de autoras e autores, como: Débora Diniz, Anahí Guedes Mello, Sara Wagner Pimenta, Robert McRuer, Amara Moira, Ana Lúcia Santos e Ana Cristina Santos.

Palavras-chave: deficiência; gênero; feminismo; capacidade compulsória; transgressão.

\footnotetext{
1 Pós-doutora em Educação. Doutora em Psicologia. Professora da Faculdade de Educação da Baixada Fluminense (FEBF) e do Programa de Pós-Graduação em Políticas Públicas e Formação Humana (PPFH), da Universidade do Estado do Rio de Janeiro (UERJ). E-mail: giovannamarafon@gmail.com

${ }^{2}$ Mestranda em Políticas Públicas e Formação Humana pela UERJ (PPFH-UERJ). Bolsista da FAPERJ. Graduada em Direito pela UFRJ e pós-graduada em Direito Público. Secretária-Geral da Comissão dos Direitos da Pessoa com deficiência da OAB/RJ. E-mail: robertapiluso@gmail.com
} 


\section{CREATIONS AND TRANSGRESSIONS IN DIALOGUE BETWEEN TRANSGENERITY AND DISABILITY: “ENTRE TRAVAS E RODAS"}

Abstract: In this article we propose to describe six episodes created for the Youtube channel "Entre travas e rodas" in which a wheelchair-bound woman (Ivone - known as "wheeled cat") and a transvestite woman (Amara Moira) talk and articulate their agendas and discussions in common, such as: the difficulties of transit through the city, the looks of strangeness and the compulsory able-bodiedness, also addressing issues related to sexuality, transsexuality, representativeness, accessibility and capacity. From this important audiovisual material with broad and free access, we analyze the relationship between gender studies and disability studies, discussing how they are articulated and how each field contributes to the other, problematizing the transversality between gender studies and disability studies to affirm transgressive bodies. For this, we take the perspective of the Social Model of Disability, with a feminist reading based on the intersectional approach, with the influence of queer and crip theories. The discussion will also cover the theoretical framework of authors, such as: Debora Diniz, Anahí Guedes Mello, Sara Wagner Pimenta, Robert McRuer, Amara Moira, Ana Lúcia Santos and Ana Cristina Santos.

Keywords: disability; gender; feminism; compulsory able-bodiedness; transgression.

\section{CREACIONES Y TRANSGRESIONES EN EL DIÁLOGO ENTRE TRANSGENERIDAD Y DISCAPACIDAD: "ENTRE CANDADOS Y RUEDAS"}

Resumen: En este artículo nos proponemos describir seis episodios creados para el canal de Youtube "Entre candados y ruedas", en los que una usuaria de silla de ruedas (Ivone Gomes conocida como "gato sobre ruedas") y una mujer travesti (Amara Moira) se encuentran y articulan sus agendas y discusiones en común, tales como: las dificultades para moverse por la ciudad, las miradas de extrañeza y la capacidad obligatoria, abordando también cuestiones relacionadas con las sexualidades, la transexualidad, la representatividad, la accesibilidad y el empoderamiento. A partir de este importante material audiovisual de amplio y libre acceso, realizamos un análisis sobre las relaciones entre los estudios de género y los estudios de la discapacidad, cuestionando cómo se articulan ambos y cómo cada campo contribuye al otro, problematizando la transversalidad entre los estudios de género y los estudios de la discapacidad para afirmar los cuerpos transgresores. Para ello, asumimos la perspectiva del Modelo Social de la Discapacidad, con una lectura feminista basada en el enfoque interseccional, con influencia de las teorías queer y creativas. La discusión también abarcará la referencia teórica de autores como: Débora Diniz, Anahí Guedes Mello, Sara Wagner Pimenta, Robert McRuer, Amara Moira, Ana Lúcia Santos y Ana Cristina Santos.

Palabras clave: discapacidad; género; feminismo; capacidad obligatoria; transgresión 


\section{Introdução}

Na sociedade contemporânea, o corpo deficiente e o corpo transgênero subvertem a lógica em que são compreendidos os corpos padronizados, criam e transgridem essas normas e afirmam outras normatividades vitais (CANGUILHEM, 2009) em que um dinamismo vital cria as condições para a "plasticidade da vida e suas infinitas possibilidades de ser vivida" (NEVES et al, 2017, p. 633). Por isso, em uma compreensão de normatividade vital, há a instauração de novas normas. Afirmando a positividade das variações, a partir da contribuição original de Georges Canguilhem, temos que: "O normal é a vida enquanto impossível de ter todas as suas formas predicadas já de saída. Dito de outro modo, o normal da vida é ser normativa" (NEVES et al, 2017, p. 633).

No entanto, diante dos enquadramentos do normal (em oposição ao que se convencionou patológico, desde uma leitura biomédica), muitos corpos enfrentam situações em que são lidos como desviantes e "anormais" (FOUCAULT, 2001), aqui entendidas como identidades fora da norma para a sociedade cisheterocompulsória e centrada na capacidade compulsória. Além disso, em nossa sociedade, é mais evidente que o gênero passe por complexos construtos sociais, enquanto em relação à deficiência nem sempre essa condição de produção tenha sido evidenciada como produção histórica, como afirmou Gavério (2015), a partir das análises de Paul B. Preciado em conferência realizada em Madrid em 2013. Embora o próprio filósofo catalão reconheça que os processos sociais, que produzem o sujeito sexual, criam também corpos como normais e patológicos; capacitados e deficientes.

Foram os estudos da deficiência que puderam pautar mais evidentemente essas relações que produzem a deficiência e permitem tomá-la como uma categoria de análise social. Ao mesmo tempo, concordando com a leitura de Gavério, tanto os estudos queer quanto os estudos da deficiência fizeram ver os processos de produção dos anormais e colocaram em xeque a ideia de normalidade, tanto no âmbito da sexualidade dissidente (da norma heterossexual compulsória) quanto da deficiência (que transgride a capacidade compulsória). Diante desse cenário, propomos refletir acerca dos estudos de gênero e sexualidade e dos estudos da deficiência de forma conjunta, percebendo de que maneira ambos podem se articular e quais as contribuições que cada campo pode trazer para o outro. Para tanto, elegemos a interseccionalidade e as teorias queer e crip como base para problematizar o que têm produzido os corpos transgressores, em aliança entre sexualidades e deficiência, corpos que foram considerados abjetos e despadronizados. Convém informar 
de modo sucinto, que entendemos queer na direção do que a teórica feminista Judith Butler preconizou e, em seus trabalhos mais recentemente publicados no Brasil, apontou a partir da leitura que a autora fez de Eve Sedgvick, que a palavra queer é um ato de fala que pode ser um desvio, "menos como como uma identidade do que como um movimento do pensamento, da linguagem e da ação que se moveu em direções bastante contrárias àquelas explicitamente reconhecidas (BUTLER, 2018, p. 69) . Assim, pensar com os estudos queer é se colocar criticamente e em contestação às normas de gênero e sexualidade historicamente hegemônicas e, nas palavras de Butler (2018), a fuga queer pode ser necessária exatamente para atingir "a viabilidade da vida fora dos seus termos" (p. 69), daqueles termos que reconhecem apenas algumas vidas em detrimento de outras. Uma qualidade queer pode abrir "espaço para novas formas de vida generificada" (p. 71).

\section{Pensando com as transgressões entre gênero, sexualidade e deficiência}

Nesta escrita, trazemos reflexões dos campos de estudos de gênero e sexualidade e da deficiência, partindo inicialmente de uma análise teórica amparada em autoras e autores referências no tema, como: Débora Diniz, Anahí Guedes Mello, Robert McRuer, Marcos Gavério, Ana Lúcia Santos e Ana Cristina Santos.

Optamos ainda por realizar uma descrição geral dos episódios disponíveis até novembro de 2019 no canal do Youtube "Entre travas e rodas" 3 e, a partir desse material, produzimos problematizações acerca da transversalidade entre corpos, com as narrativas de uma mulher transgênera e de uma mulher com deficiência, mais centrada em elementos que emergiram no primeiro episódio, como veremos adiante.

No canal do Youtube, uma mulher cadeirante (Ivone - conhecida como "gata de rodas") e uma mulher travesti (Amara Moira) se encontram com o objetivo de colocar em diálogo as pautas e discussões que têm em comum, tais como: as dificuldades de transitar pela cidade, os olhares de estranhamento alheio e a capacidade compulsória, abordando ainda questões relativas a sexualidades, transexualidade, representatividade, acessibilidade e capacitismo. Com Amara Moira, entendemos que a transexualidade está no centro de uma construção, emergindo dessa construção a necessidade de nomear a cisgeneridade - "O cis pelo trans". Moira (2017) enfatiza que o termo trans, da década de 1920, precedeu o cis em

3 O Canal "Entre travas e Rodas" está disponível no Youtube: https://www.youtube.com/channel/UCntypRcBeRIAaPfWKz41pQ 
70 anos! O cis diz de quem escreve, de onde se escreve e com que se identifica, em última instância, relaciona-se à autoidentificação. E numa cultura cissexista, com dificuldade de se ver enquanto tal, o trans é que foi destacado como impossibilidade, a ver:

numa sociedade tão cissexista que sequer conseguisse enxergar o próprio cissexismo (de tão naturalizada que estava essa lei, de tão apagada que estava a sua origem, a sua razão), não haveria a menor possibilidade de pensarmos a existência material, concreta de pessoas trans. Por obra da violência transfóbica, que tem suas bases bem fincadas no sexismo, aquelas pessoas que ousassem afrontar essa lei seriam mortas ou teriam que voltar de imediato para o armário, dando a impressão falsa de que inexistiam ou de que desexistiram (MOIRA, 2017, p. 365-366, grifo do autor).

Mais ainda, então, importa nomear o cis e reconhecer as pessoas trans, elas existem. Fazendo frente à transfobia, é preciso mostrar as existências trans, as formas de vida que criam e as transgressões que realizam. Na mesma direção, importa pensar acerca do capacitismo que ocorre quando há discriminações por motivo de deficiência. Com Anahi Guedes de Mello, compreendemos que o capacitismo seria um neologismo para se referir ao preconceito contra pessoas com deficiência e sua proveniência seria estruturante das relações sociais (MELLO, 2016, p. 3266). Assim, para a matriz eugênica, os deficientes foram e são encarados como os degenerados, os anormais, aqueles que não devem se reproduzir e deveriam, portanto, ser descartados. A antropóloga e pesquisadora, no texto "Entre Pesquisar e Militar: engajamento político e construção da teoria feminista no Brasil" (MELLO et al., 2013) narrou ainda a dificuldade e resistência iniciais de incorporação do termo capacitismo nos documentos finais da III Conferência Nacional de Políticas para Mulheres. Em contrapartida, na II Conferência Nacional de Políticas Públicas e Direitos Humanos de LGBTs, Anahi conseguiu que o termo capacitismo fosse incluída nas diretrizes de alguns dos eixos daquela Conferência, produzindo uma importante articulação entre a luta LGBT e a luta da deficiência.

Neste texto, portanto, seguimos problematizações que consideram o problema de pesquisa como uma estratégia metodológica, na qual o método se localiza na análise prática e na observação, tendo os conceitos como ferramentas que nos auxiliam a perceber novas formas de ver e falar, conceitos dos dois campos de estudo de gênero e da 
deficiência tornaram-se fundamentais e estabeleceram um modo de pensar a pesquisa (BERNARDES et al, 2016, p. 77). São os conceitos que forjam um pensamento, não estando dentro nem fora daquele que pensa, sendo condições para um pensamento possível. Com isso, seguindo na esteira dos modos de pesquisar e escrever foucaultianos, temos na problematização um caminho de investigação. Criar problemas, fazer questões em vez de tomar como dados determinados temas. A transgeneridade e a deficiência são efeitos de práticas sociais, não são atributos de corpos em si mesmos, isoladamente. É por isso "que se abre um campo de problematizações sobre como as 'coisas' tornam-se problemas" (BERNARDES et al, 2016, p. 84).

Nossa intenção é abordar as relações entre os estudos de gênero e sexualidade e os estudos da deficiência, com base nessas pautas em comum e interrogando como os campos se articulam. Almejamos compreender, ainda, como cada campo contribui para o outro, problematizando a transversalidade entre os estudos de gênero e os estudos da deficiência para afirmar corpos que transgridem a capacidade e a heterossexualidade compulsórias. Nesse sentido, encontramos que a crítica aos discursos normalizadores seria "um dos pontos de encontro entre leituras críticas da sexualidade (teoria queer) e leituras críticas da deficiência (disability studies)" (GAVÉRIO, 2015, p. 105, grifo do autor). Para dar continuidade a essa análise, assumimos a perspectiva do Modelo Social da Deficiência (DINIZ, 2007), especialmente com a crítica feminista ao modelo social e com a leitura feminista pautada em uma abordagem interseccional, com influência das teorias queer e crip. Aqui, crip diz respeito aos estudos e à articulação teórica que permite que se subverta o que era ofensivo, um xingamento, em relação aos corpos das pessoas com deficiência, ditas "aleijadas". Assim, crip é uma politização que entrecruza a analítica dos corpos com deficiência e a teoria queer.

\section{Corpos abjetos e a teoria Crip}

O corpo deficiente e o corpo travesti subvertem a lógica cisheteronormativa e capacitista, mas são pensados enquanto corpos abjetos nesta sociedade, como aqueles que não deveriam existir e por isso são invisibilizados em muitos estudos acadêmicos e no dia a dia da sociedade. Pensamos a abjeção dos corpos na direção do que propõe Gabriel de Oliveira Rodrigues, enquanto vidas invisibilizadas, apagadas e, em última instância, como se não pudessem existir: 
A abjeção inclui corpos cuja vida não é considerada uma vida: sua materialidade não é importante. E é no discurso que a abjeção é construída, principalmente por meio do apagamento, do não dizer, do território proibido, do indizível, daquilo sobre o que ninguém quer falar. Quando impossível apagar, o discurso trata tais corpos com uma "distância do eu", sempre salientando que são corpos inviáveis, que pertencem à noite, à margem, que não são (devem ser) vistos à luz do dia nos passeios públicos das pessoas de bem, nem acessíveis aos olhos do cidadão comum (RODRIGUES, 2018, p. 31).

Para desenvolver os efeitos do olhar que produz a abjeção dos corpos, acreditamos ser apropriado abordar a teoria crip, importante baliza nos estudos da deficiência com apoio nas leituras de Robert McRuer, Anahi Guedes de Mello e Marcos Gavério, referências sobre a teoria crip no mundo e no Brasil.

Segundo Anahi Guedes de Mello (2016), a teoria crip, voltada ao estudo das deficiências, segue a mesma lógica da teoria queer, voltada a problematizar as sexualidades não hegemônicas ou, como afirma Gavério (2015), sexualidades dissidentes. Nesse contexto, o impacto da teoria queer se reflete nos estudos da deficiência e contribui para a emergência de uma teoria crip. Retomando McReuer, Gavério (2015), afirma que existe "uma acessibilidade entre posições críticas queer e deficientes [queer-crips]" (GAVÉRIO, 2015, p. 105, grifo do autor)

Enquanto a teoria queer postula que a sociedade é regida por uma heteronormatividade compulsória, o postulado máximo da teoria crip é de que a sociedade contemporânea se sustenta na capacidade compulsória ${ }^{4}$, em uma estrutura social pouco sensível à diversidade corporal, na qual a pessoa deficiente destoa da suposta hegemonia e na qual existe uma gradação da corporalidade em virtude da ideia de normalidade.

Nesse sentido, a teoria crip provoca fissuras na teoria queer para que ela passe a incorporar também a deficiência. A palavra "crip", em inglês, significa aleijado, abordando a teoria, portanto, os corpos aleijados, revelando uma problematização do que é considerado abjeção dos corpos das pessoas com deficiência. Na proposta de

\footnotetext{
${ }^{4}$ Agradecemos à Anahi Guedes de Mello pela sugestão de traduzir compulsory able-bodiedness, do inglês, para capacidade compulsória, em português.
} 
Gavério (2015), uma teoria crippled, que aleijasse os saberes queers, por meio do saber crítico da deficiência dos anos mais recentes.

O termo crip, em inglês e português, é propositalmente agressivo, pejorativo e subversivo com a finalidade de marcar uma analítica da normalização dos corpos de todos os que fogem aos padrões corporais/funcionais/cognitivos marcados por uma capacidade compulsória. Segundo Robert McRuer:

I would argue, however, as others have, that feminist and queer theories (and cultural theories generally) are not yet accustomed to figuring ability/disability into the equation, and thus this theory of compulsory ablebodiedness is offered as a preliminary contribution to that much-needed conversation (MCRUER, 2002, p. 89).

McRuer utilizava a expressão compulsory able-bodiedness que contemplaria a tradução de able-bodied para o português como "apto", contudo, dependendo do contexto das frases usadas com este termo, seria possível traduzir como corpos hábeis, aptos, capazes ou, ainda, sem deficiência. No entanto, ao invés de "aptonormatividade", Anahi Guedes de Mello (2016) propõe adotar o termo "corpos capazes" ao invés de "corpos aptos". Aqui adotamos o termo "capacidade compulsória" para traduzir compulsory able-bodiedness. Com esse termo entendemos que a deficiência aleija o queer, e traz a capacidade para uma compreensão tal qual a da heterossexualidade, ambas em modo compulsório na fabricação de modos de viver na nossa sociedade.

Se pensarmos na esteira de Adrienne Rich (2010), em um texto clássico, originalmente dos anos 1980, a heterossexualidade compulsória é uma instituição política que retira o poder das mulheres e também é uma ideologia. Hoje diríamos, a tal "ideologia de gênero" que grupos conservadores temem perder e por isso investem tanto na propaganda cultural heterossexual e tentam a todo custo demonizar qualquer outra maneira de pensar as sexualidades que escape da referência dominante. Para além da heterossexualidade, afirma Miskolci (2009, p. 156-157):

a heteronormatividade é um conjunto de prescrições que fundamenta processos sociais de regulação e controle, até mesmo aqueles que não se relacionam com pessoas do sexo oposto. Assim, ela não se refere apenas aos sujeitos legítimos e normalizados, mas é uma denominação contemporânea para o dispositivo histórico da sexualidade que evidencia seu objetivo: formar todos para serem heterossexuais ou organizarem suas vidas a partir do modelo supostamente coerente, superior e "natural" da heterossexualidade. 
A heteronormatividade faz parecer que a heterossexualidade seria "natural" e o único fundamento aceitável da ordem social, constituindo-se como poder de regulação das vidas e das condutas e uma força normalizadora agindo sobre todos, inclusive sobre as pessoas com deficiência.

\section{Trangressões: a importância da ferramenta da interseccionalidade}

Propomos pensar corpos transgêneros e corpos com deficiência desde uma perspectiva interseccional, que articula as discussões e que faz refletir ainda sobre outras intersecções possíveis quando se problematiza a vida a partir desses corpos. Autoras e intelectuais negras brasileiras, como Lélia Gonzalez e Sueli Carneiro, já abordavam as questões sociais das desigualdades pelo viés interseccional, desde as décadas de 1970/80 (CARNEIRO, 2011; GONZALEZ, 1984), especialmente ao problematizarem o racismo e o sexismo.

Nesse sentido, com Akotirene (2018), a interseccionalidade é uma sensibilidade analítica pautada pelas mulheres negras para pensar sistemas de opressão, que pode ser entendida como um aporte para o estudo da relação entre identidades sociais e sistemas relacionados de opressão, discriminação e dominação, permitindo compreender a colisão das estruturas, a interação simultânea das avenidas identitárias, além do fracasso de um feminismo mais clássico em contemplar mulheres não brancas, com deficiência, pessoas transgêneres, entre outras.

A interseccionalidade procura examinar como os chamados eixos identitários ou avenidas identitárias ou encruzilhadas que interagem em níveis múltiplos e muitas vezes simultâneos e como as formas de opressão se inter-relacionam, criando um sistema de opressão que reflete o cruzamento de múltiplas formas de discriminação. Cabe dizer que, geralmente, as mulheres com deficiência e as mulheres trans acabam sendo alocadas como "outras", depois da nomeação de outros marcadores sociais, como: classe, raça e gênero. Pouco se aborda ainda na academia a questão da deficiência e da transgeneridade, mesmo no âmbito das ciências sociais, do direito, da psicologia e da educação. Entendemos que a articulação interseccional pode se beneficiar e ampliar 
com o diálogo crip, que explicita e reconhece tanto a deficiência quanto o corpo trans como modos de vida.

Nessa perspectiva, não interessam aforismos matemáticos hierarquizantes ou comparativos, não sendo a soma matemática de identidades ou opressões o que está em questão, mas uma análise de quais condições estruturais atravessam os corpos, quais posições reorientam significados subjetivos desses corpos, por terem experiências fundadas na interação das estruturas opressoras. Assim, para Akotirene (2018), não existe hierarquia de opressão, sendo a interseccionalidade uma sensibilidade analítica que se refere ao que faremos politicamente com a matriz de opressão responsável por produzir diferenças e desigualdades, depois de enxergá-las como identidades.

A autora afirma que o Feminismo Negro dialoga concomitantemente entre e com as encruzilhadas ou avenidas identitárias do racismo, cisheteropatriarcado e capitalismo. Dessa forma, o que se produz nesse campo discursivo precisa ser aprendido pelo restante da população, em especial por lésbicas, gays, bissexuais, transexuais, queers e intersexos (LGBTQI+), pelas pessoas com deficiência, indígenas e trabalhadoras/es. Não mais é possível ignorar a matriz fundante e basilar que padroniza e administra todas as opressões contra mulheres, construídas heterogeneamente nestes grupos, vítimas das colisões e encruzilhadas múltiplas do capacitismo, terrorismo religioso, cisheteropatriarcado e imperialismo.

O direito fundamental à igualdade, sem distinção de qualquer natureza, está previsto e assegurado no artigo 5o da Constituição da República Federativa do Brasil. Assim, Akotirene (2018) afirma que, caso os instrumentos protetivos do país queiram, verdadeiramente, combater as discriminações que impedem o pleno exercício dos direitos fundamentais, precisam averiguar as performances sexistas e racistas (e aqui também nomeamos capacitistas) dos seus expedientes utilizando a abordagem interseccional. Ao que acrescentamos, pela argumentação até aqui apresentada, o diálogo queer-crip, assumindo uma teoria crippled.

\section{O Canal "Entre Travas e Rodas" - intersecções queer-crips entre trans e "defiças"}

Vínhamos de experiências na pós-graduação interdisciplinar com leituras e discussões de textos que faziam pensar as conexões e transversalidades entre gênero, sexualidade e

\footnotetext{
${ }^{5}$ Tomamos a liberdade de usar o termo "defiças" tal como Anahi Guedes de Mello e Sara Wagner Pimenta Gonçalves Junior apresentaram na chamada para o presente dossiê.
} 
deficiência, desde um interesse em cruzar os campos dos estudos de gênero e sexualidade e os estudos da deficiência em nossos projetos. Foi nesse contexto que soubemos, naquele momento, da recém criação do Canal "Entre Travas e Rodas", idealizado por Amara Moira travesti, prostituta, escritora, professora, doutora em Estudos da Linguagem/ UNICAMP, feminista e militante dos direitos LGBT's (T's em especial) e de profissionais do sexo - e Ivone Gomes de Oliveira - blogueira (criadora do blog Gata de rodas), militante e ativista pela diversidade sexual, formada em Psicologia.

Nossa atenção se voltou a acompanhar cada episódio na medida em ocorriam os lançamentos, divulgados pelas redes sociais. Conforme assistíamos, evidenciava-se a forca e a potência da articulação que Amara e Ivone, juntas, estavam produzindo e oferecendo ao mundo. Uma produção situada, implicada com a intervenção na realidade e muito valiosa para os estudos acadêmicos e militantes.

Escolhemos então descrever e analisar os episódios do Canal "Entre Travas e Rodas" justamente em virtude das intersecções e interações entre as demandas das mulheres que o apresentam. Amara e Ivone afirmam o aspecto político de suas identidades e dissidências sexuais, tal como afirmou Gonçalves Júnior (2018): “Os oprimidos podem e devem falar por si mesmos. Eu, como mulher travesti, não permito que meu discurso seja invalidado ou menor" (p. 18). Da mesma maneira, Amara e Ivone falam por si mesmas, são conhecidas nas redes sociais pelos seus ativismos e, por meio do canal audiovisual, mostram a vida das pessoas com deficiência e travestis como é para elas, especialmente na cidade de São Paulo, local onde moram.

As duas mulheres são consideradas corpos "estranhos" ou abjetos, que transitam por uma grande cidade aparentemente plural. A luta do canal e dessas mulheres militantes é estar num mundo onde não se estranhe a presença de seus corpos, onde seus corpos possam existir plenamente e com dignidade. A seguir, traremos narrativas do que vimos, ouvimos e percebemos de modo amplo em cada episódio do Canal.

No primeiro episódio (chamado “Que canal é esse, minha gente?"), Amara afirma que a vontade delas era fazer as pessoas olharem o mundo da perspectiva que elas o veem, percebendo todas as limitações e obstáculos que são criados para pessoas com deficiência e 
trans e demais pessoas LGBTQI+s, mulheres etc., compreendendo que as demandas sociais e as situações podem ser muito mais parecidas do que se perceberia à primeira vista. Apontam, por exemplo, os olhares de estranhamento que recebem, como é para esses corpos transitarem pelas ruas e por espaços tão cotidianos como os banheiros, mas que para ambas podem se tornar de difícil acesso e trânsito, sendo mais um lugar de enquadramento de seus corpos e de exclusão. Nesse sentido, lembramos de Judith Butler (2015) e a definição da autora quanto aos enquadramentos, às molduras pelas quais aprendemos e somos levados a apreender a vida dos outros, seja como vida vivível, perdida ou lesada. A autora destaca que se tratam de operações de poder, saturadas de ações políticas, nada neutras.

No segundo episódio ("Brincando de Fazer Revolução), as apresentadoras contam como se conheceram: na Caminhada da Visibilidade Transexual (um ato político, que acontece anualmente no dia 26 de janeiro). Ivone foi ao evento com uma bandeira trans em sua cadeira de rodas, mas naquele primeiro momento não sabia muito bem o significado e quando questionada sobre o motivo de estar ali esclareceu que não era necessário ser do "segmento T" para ser contra a transfobia. Lá conheceu Amara e passaram a manter contato pelas redes sociais.

Nesse segundo capítulo, Amara reforça as semelhanças entre questões trans e de pessoas com deficiência, tais como: transitar pela rua, transição dos corpos, olhares direcionados a elas com estranhamento (não necessariamente hostil), atitudes/posturas agressivas, pessoas que são consideradas estorvos e que teriam momento específico e restrito para transitar pela cidade. Uma excelente informação trazida nesse episódio é que Ivone, em 2017, conseguiu tornar a parada LGBTQI+ um evento com acessibilidade para pessoas com deficiência na cidade de São Paulo.

Geralmente não se pensa que pessoas com deficiência tenham um posicionamento político e/ou de gênero e uma orientação sexual alinhada às dissidências, por que por muito tempo predominou a ideia limitadora da sexualidade das pessoas com deficiência. A partir das narrativas de mulheres deficientizadas, em Portugal, em estudo acerca da cidadania íntima, Ana Lúcia Santos e Ana Cristina Santos encontraram que: "o estigma da deficiência nega às pessoas o acesso à sexualidade, sendo que a dificuldade em reconhecer o desejo erótico na deficiência é agravada quando se trata de corpos não normativos", dizem-nos Santos e Santos (2019, p. 144). Quando Ivone ocupa um lugar na parada LGBTQI+, ela leva consigo muitos outros corpos em dissidências e pratica transgressões de fronteiras 
normalizadoras. O gesto que ela protagonizou transversaliza questões incorporadas na pauta de luta social e política pela visibilidade dos corpos.

O terceiro episódio ("Descobrindo nossos corpos") aborda as transições e descobertas em relação aos próprios corpos. Amara conta que havia começado sua transição cinco anos antes. Com 18 anos de idade, a professora e ativista já se assumia bissexual, mas como corpo transgênero ela se apresentou aos 29 anos, ressaltando ainda que foi somente nessa idade, depois da transição, que as pessoas passaram a tocar nela sem que ela consentisse. Ela percebeu e analisou que antes, quando se apresentava no gênero masculino, sendo lida como homem, algo assim nunca havia lhe acontecido. Resta o questionamento se, em nossa sociedade, quando uma vida se apresenta e é lida como uma mulher abre-se o caminho da invasão desse corpo e a violação de sua intimidade e privacidade. Quais corpos são passíveis de respeito? Quais são desrespeitados?

Ivone também relatou ser bissexual e que enquanto mulher com deficiência foi criada para não ter desejo ou prazer, infantilizada, para não vir a ter um relacionamento. Ela apresentou sua orientação sexual, interseccionada pela experiência de mulher com deficiência. Seu primeiro relacionamento, na adolescência, com um rapaz, foi marcado por intenso preconceito masculino e pelo constrangimento que o estereótipo do corpo perfeito criava. Naquela experiência, o rapaz dizia que gostava muito dela, mas não queria ser visto com ela como namorada na frente de todo mundo.

Além disso, a mãe de Ivone brigou com ela quando descobriu que ela tivera uma relação, falando que a filha não tomava conta nem dela mesma, e por isso "não teria como dar conta de um relacionamento com outra pessoa". Percebemos que essa narrativa encontra eco em muitas outras, não ouvidas ou até mesmo nunca expressadas, mas vividas. Recai sobre as mulheres um controle da sexualidade que fabrica as condições de possibilidade e impossibilidade para muitas, especialmente para as mulheres com deficiência. Ao mesmo tempo em que são tratadas como aquelas que não deveriam ter uma vida sexual, elas também são alvos de violências variadas, inclusive sexuais. Há ainda uma subnotificação referente à magnitude da violência contra a mulher com deficiência no Brasil embora, segundo a Organização das Nações Unidas (ONU, 2019), elas tenham três 
vezes mais probabilidade, em média, de sofrer violência baseada em gênero em comparação com as mulheres sem deficiência.

O relato de Ivone leva a perceber as diversas manifestações de capacitismo que podem atravessar a vida de uma pessoa com deficiência: vista como incapaz para namorar, para transar, para cuidar de si etc. O olhar da falta e do déficit, direcionado à mulher deficiente, não encontra correspondência na vida que Ivone vive, cheia de possibilidades. Nesse aspecto, como asseveram as autoras portuguesas, do ponto de vista teórico, se a vida sexual for um amplo espectro de possibilidades, "tal como sucede empiricamente, a diversidade funcional será mais um contributo para o enriquecimento de práticas sexuais" (SANTOS; SANTOS, 2019, p. 148). Amara comenta nesse aspecto a ocorrência da eterna infantilização da pessoa com deficiência, que muitas vezes fica ainda escondida das pessoas em casa. Logo se evidencia o princípio capacitista que determina o entendimento do sexo e recai sobre muitas pessoas com deficiência. Amara abordou também a importância de lutar para que as pessoas possam experimentar, brincar com papéis sociais, exercer livremente ideias do que é masculino e/ou feminino e transitar entre espaços para ver onde se sentem mais confortáveis em suas existências. Isso ultrapassaria a ideia normativa e cisheterocapacitista da sexualidade que, "para além de excludente e redutora, constrange a liberdade de movimentos mais do que as próprias limitações físicas" (SANTOS; SANTOS, 2019, p. 154).

O episódio 4 ("A cidade é nossa") aborda a relação dos corpos transgêneros e das pessoas com deficiência na relação com a cidade. Ivone e Amara começaram com a importante e impactante frase: "uma cadeirante incomoda muita gente, uma travesti e uma cadeirante incomodam muito mais". Elas destacam a relevância do encontro e do incômodo em relação ao que está dado, e o que elas podem produzir juntas. Essa é a aposta.

A cidade de São Paulo é o local em que Amara começou a transição e a cidade em que Ivone nasceu. Como moradora da zona leste (Itaquera), isto é, uma região periférica, Ivone relata que na juventude não existiam calçadas para transitar e ela andava muito com o auxílio da família, dificilmente andava sozinha. Ivone relatou que ouviu uma frase muito forte no metrô, quando estava voltando do trabalho e uma senhora falou: "o que você está fazendo aqui agora? Isso não é horário pra você". Essa fala repleta da certeza inconteste de que Ivone teria "escolhido" o pior horário para se deslocar reforça que a sociedade vê os corpos tidos como abjetos como os corpos que não podem transitar em qualquer lugar e em qualquer horário, negando para Ivone a possibilidade que ela tenha uma vida ordinária, 
comum, de alguém que pega o metrô na volta do trabalho no mesmo horário da maioria de trabalhadoras/es.

Em realidade, o constrangimento não deveria advir de transitar nos locais inacessíveis, mas sim pelo fato de um local não ser acessível. Amara fez importante observação naquele momento afirmando que "é preciso que essa cidade não seja esse turbilhão de 200 por hora, porque nem todo mundo pode andar 200 por hora e quem não pode ficaria excluído e isso não é tolerável". Essa ponderação de Amara Moira faz pensar como a lógica capitalista, que impõe velocidades aceleradas, exclui muitos corpos.

Em contrapartida, ainda que enfrente também o tabu de quando e onde o corpo trans pode circular, Amara afirma que em São Paulo ela consegue existir, sem ser relegada a subempregos ou à prostituição precária, mal remunerada (comumente a forma laboral que resta para pessoas trans - majoritariamente excluídas da escola, das famílias e do circuito de trabalho. Nesse ínterim, elas reafirmam a importância de transitarem pela cidade (independentemente de local ou horário), pois a partir desse transitar as pessoas estão olhando mais para os corpos não padronizados e com isso podem pensar e se familiarizar com a existência de corpos diversos.

Ivone e Amara reafirmam outro ponto em comum entre travestis e pessoas com deficiência, qual seja, que as pessoas olham, apontam e dizem coisas a elas, se dão ao direito de olhar ou até tocar seus corpos (sem consentimento), como se fossem intrusas nos espaços e, por isso, relegadas a sofrer toda sorte de desrespeitos. Muitas pessoas transgêneras e com deficiência acabam não querendo sair de casa por conta dessa conduta de outros (com desrespeitos e humilhações). Como se o espaço público não fosse para todas, todos e qualquer um/a. Como se determinadas pessoas só pudessem transitar com determinado corpo em determinado horário.

O quinto episódio (Hora da Cama!) começa com os dois corpos lidos como abjetos conversando sentadas sobre uma cama e falando que ambas possuem uma relação de diferenciação de sentidos com as palavras "corpo", "sexualidade" e "sensibilidade". Ivone relatou questionamentos que recebeu quanto a ter sensibilidade no corpo e explicou que 
cada deficiência tem sensibilidades e não sensibilidades. Ela, por exemplo, sente carinho nas pernas. Por isso ela afirmou que cabe a cada um se conhecer e encontrar o que lhe dá prazer.

Amara afirmou que cada pessoa tem sensibilidades, vergonhas (a sociedade produz isso, da busca do corpo perfeito, do que pode ser apresentado para a família do namorado etc.) e que há belezas e potências em todos os corpos. Afirmou ainda que fomos criados para acreditar que certos corpos são menos prazerosos do que outros. Desejo sobre corpo existe, mas muita gente não quer assumir publicamente. Para ela, isso refletiria um panorama torto da sociedade que deseja, mas não assume que deseja. Ela entende que a experiência erótica da sociedade é muito limitada e muito limitadora. Por isso, a proposta do canal é diminuir limitações, é "trazer a família brasileira para a cama".

O último episódio disponível até novembro de 2019 no canal é o sexto ("Mês do Orgulho pra travesti e pra cadeirante!"). Depois de algum tempo sem novos vídeos, elas falaram que "voltariam com tudo!". Elas têm sido chamadas para muitas atividades fora do vídeo, para debates etc. Isso mostra o efeito de ampliação da discussão e de visibilidade e intervenção na realidade que elas vêm produzindo. Esse episódio se inicia com uma fala de Ivone acerca da dificuldade para chegar até a Vila Madalena para gravar em local acessível e a dificuldade de acessibilidade que ela encontra em geral, no trem (transferências), metrô, ônibus e calçadas difíceis de transitar.

A Gata de rodas afirmou ainda que "seu Stonewall" começou em 2017, quando conseguiu colocar pessoas com deficiência LGBTQI+ na rua, no centro, na parada do orgulho LGBTQI+ de São Paulo. Ela afirmou que a organização da Parada tem um grupo de trabalho (GT) específico para pessoas com deficiência LGBTI's.

Amara diz não gostar tanto de multidões e aglomerações, mas, para ela, no mês do orgulho também são marcantes eventos menores, como a Marcha Trans (em seu segundo ano consecutivo e focada na letra " $\mathrm{T}$ ", com muitas músicas e corpos trans por metro quadrado) e a Caminhada de Mulheres Lésbicas e Bissexuais (ela lembra que travestis também podem ser lésbicas e bissexuais). Interessante notar o relato tanto de mães LGBT's participando dos eventos, como familiares de pessoas com deficiência e, especialmente, pessoas transgêneras e com deficiência. 
Análise jurídico-social do direito ao uso dos banheiros: articulações entre lutas trans e "defiças"

A partir da problematização do uso dos banheiros, apresentada por Amara e Ivone no primeiro episódio, problematizamos a reivindicação dos direitos por pessoas trans e por pessoas com deficiência e nos inquietamos com possíveis semelhanças e diferenças entre as lutas pela visibilidade e dignidade dos corpos. Ainda é frequente vermos notícias de situações em que pessoas trans foram constrangidas e não puderam usar o banheiro de sua escolha, portanto, em algumas situações a utilização do banheiro tem se tornado, , uma batalha judicial para pessoas trans no Brasil. Inúmeros casos foram judicializados pelo país quando pessoas trans foram (e muitas vezes ainda são) impedidas de utilizar o banheiro público designado para o gênero com o qual se identificam. A questão acabou chegando ao Supremo Tribunal Federal (Recurso Extraordinário no 845.779- SC) e, depois dos Ministros Luiz Roberto Barroso e Edson Fachin votarem a favor do uso do banheiro conforme a identidade de gênero da pessoa usuária, o ministro Luiz Fux pediu vista do processo em 2015 e o julgamento encontra-se parado até o momento ${ }^{6}$ (BRASIL, 2014). Contudo, já existem decisões de tribunais pelo país validando o uso dos banheiros de escolha das pessoas trans e reforçando o direito de liberdade e de não discriminação da população trans no acesso aos locais públicos, especialmente banheiros, inclusive com o arbitramento de indenizações quando houver a violação a tal direito?.

Nesse contexto, no mesmo ano que o Supremo iniciou o julgamento, o Conselho de Combate à Discriminação e Promoção dos Direitos dos LGBT's, que em 2019 foi encerrado pelo presidente Jair Bolsonaro, emitiu a Resolução no 12, na época assinada pela então presidenta Dilma Roussef, que determina regras de respeito às pessoas trans dentro de instituições de ensino e em documentos públicos ${ }^{8}$. Entre outros pontos, o acesso ao

\footnotetext{
${ }^{6}$ Consulta ao processo realizada em 06 de fevereiro de 2020. Para acompanhar o andamento do referido processo: http://portal.stf.jus.br/processos/detalhe.asp?incidente $=4657292$

${ }^{7}$ Nesse sentido, conferir a decisão da Apelação Cível proferida no processo no 0435447-18.2016.8.21.7000 do Tribunal de Justiça do Rio Grande do Sul. Link: https://www.conjur.com.br/dl/apelacao-tj-rs-transexualdireito.pdf. Acesso em 05 de fevereiro de 2020.

8 A Resolução encontra-se disponível no link: http://www.lex.com.br/legis 26579652 RESOLUCAO N 12 DE 16 DE JANEIRO DE 2015.aspx.
} 
banheiro se encontra no artigo 6o da mencionada resolução, afirmando que: "deve ser garantido o uso de banheiros, vestiários e demais espaços segregados por gênero, quando houver, de acordo com a identidade de gênero de cada sujeito" (BRASIL, 2015).

No mesmo sentido, o Ministério Público Federal já se manifestou, em Parecer enviado pelo então Procurador Geral da República (PGR) ao STF, defendendo autodeterminação de gênero e afirmando que a identidade sexual está ligada à dignidade da pessoa humana e aos direitos da personalidade, assim, pessoas trans não poderiam ser proibidas de usar banheiro do gênero com o qual se identificam.

Com a referência de Roger Raupp Rios e Alice Hertzog Resadori (2015), pensamos que a utilização de banheiros públicos por transexuais é direito fundamental, protegido constitucionalmente pela dignidade humana9. A violação de tal direito, fere o direito fundamental à autodeterminação sexual e os direitos de liberdade e igualdade, presentes tanto na Constituição da República quanto nos tratados internacionais dos quais o Brasil é signatário.

Com efeito, em que pese abordar mais a questão da mudança de nome de acordo com a identidade de gênero e também sobre o reconhecimento dos direitos econômicos derivados de união homoafetiva, a importante Opinião Consultiva no 24 emitida pela Corte Interamericana de Direitos Humanos de 2017 (CIDH 24/17) igualmente reforça as garantias já estabelecidas pela Convenção Americana de Direitos Humanos (CADH)/ Pacto de San Jose da Costa Rica sobre identidade de gênero e não discriminação. Nesse sentido, a Opinião Consultiva no 24 reitera a jurisprudência da Corte no sentido de que a orientação sexual e a identidade de gênero são direitos protegidos pelo sistema interamericano e de que o direito à identidade de gênero está vinculado às garantias de liberdade e de autodeterminação, sendo o reconhecimento por parte dos Estados integrantes da OEA, como é o caso do Brasil, de vital importância para o pleno gozo dos direitos humanos.

Quanto ao uso dos banheiros pelas pessoas com deficiência, um recente estudo internacional realizado pela ComRes, instituição de pesquisa britânica, para a Toyota Mobility Foundation, afirma que mais da metade dos brasileiros cadeirantes (55\%) não conseguem encontrar um banheiro acessível quando precisam (PAMPLONA, 2018). Isso apenas quando

\footnotetext{
${ }^{9} \mathrm{Em}$ que pese os autores apenas mencionarem transexuais femininas, acreditamos que o direito se estende a toda a população trans.
} 
se aborda as pessoas que utilizam cadeira de rodas, sem mencionar outros tipos de barreiras arquitetônicas que inviabilizam o uso dos banheiros por pessoas com deficiência em geral.

Nesse aspecto, percebemos semelhanças e diferenças entre as lutas trans e das pessoas com deficiência. Há semelhanças nas dificuldades encontradas para acesso e uso dos banheiros, mas há diferenças quanto ao olhar socialmente dominante que se escandaliza com os corpos trans que usam banheiros binariamente repartidos entre femininos e masculinos, seguindo critérios de continuidade linear entre o que se convencionou nomear sexo genital (ou biológico, sendo essa também uma construção cultural e da linguagem), e identidade de gênero.

Em relação aos corpos com deficiência, idosos e/ou de pessoas com mobilidade reduzida, não há pânico social diretamente associado; há certa complacência, embora distante de reais mudanças arquitetônicas e de remoção das barreiras interpostas. Assim, ao denunciar as violações de direitos ao uso dos banheiros, a população travesti e transexual tem conseguido mais efetividade no acesso a tais espaços, especialmente em universidades e órgãos públicos. Enquanto entre a população com deficiência, parece que ainda paira a invisibilidade da questão do acesso aos banheiros e seu uso - o que, em última instância, pode ser um grave impedimento para que corpos "defiças" possam ter uma vida ordinária, como qualquer outra pessoa. Aqui, percebemos que a problematização do uso dos banheiros feita na relação entre pessoas trans e "defiças" ganha na sua articulação mútua, dando visibilidade uma à outra e ampliando a politização do debate acerca da vida no aspecto que parece privado, mas diz das condições partilhadas socialmente para uma vida digna. Isso corresponde ao direito à cidade, à casa, aos espaços de saúde e educativos, entre outros, como espaços para todos os corpos e qualquer um.

\section{Considerações finais}

Pensando com o canal "Entre travas e rodas" acreditamos ser importante afirmar a teoria crip como um caminho por meio do qual é possível estabelecer diálogos e relações entre transgeneridade, deficiência e sexualidades não normativas. 
Existem eixos de articulação em comum que precisam ser observados, bem como a dificuldade de incorporação da interseccionalidade no campo de ação das políticas públicas (de gênero e sexualidade para a deficiência) no Brasil. Dessa forma, a importância da transversalidade entre a deficiência e as políticas de gênero e sexualidade pretende gerar uma reflexão político-teórica do feminismo, antirracista e anticapacitista, propondo-se a incorporação de demandas que considerem as vidas das pessoas com deficiência e as vidas transgêneras como modos de vida, sendo este um problema ético, como afirma Butler (2015). Esse duplo movimento e sua relação podem compor novas agendas e novas linguagens para corpos transgressores.

As falas e intervenções de Ivone e Amara mostram a relevância da discussão conjunta entre "travas e rodas", trazendo à visibilidade narrativas de vidas que existem e almejam reconhecimento como vidas que têm valor e, parafraseando Butler (2015, p. 17): "depende[m] de normas que facilitem esse reconhecimento". Ao mesmo tempo, podemos fazer críticas das normas de reconhecimento estabelecidas socialmente e, com a lente crip, forçar aberturas e invenções que ultrapassem a normatividade capacitista e cisheterossexista. As narrativas de Amara e Ivone oportunizam que um público amplo acompanhe, em linguagem bastante direta e comunicativa, os percalços pelos quais elas passaram com seus corpos nos mais variados espaços, desde os geográficos, aos afetivos, relacionais e sexuais. Revelam, com isso, alguns sofrimentos psicossociais que advém de viver em uma sociedade cisheteronormativa e baseada na capacidade compulsória e parecem disputar novas condições de ser reconhecidas. Elas, então, questionam a moldura e mostram que é possível reinventar os prazeres, os caminhos das sensibilidades dos corpos, lutar pela igualdade sexual e pelo viver que cria novas normas de gênero, sexualidades e corporalidades, cheias de possibilidades.

\section{Referências}

AKOTIRENE, C. O que é interseccionalidade? Belo Horizonte: Letramento, 2018.

BERNARDES, A. G et al. Problema de Pesquisa como uma estratégia metodológica. In: Ferreira, Marcelo e Moraes, Marcia (orgs). Políticas de pesquisas em psicologia social/ Rio de Janeiro: Nova Aliança Editora e Papéis, 2016, p. 73 - 92.

BRASIL. Secretaria de Direitos Humanos. Conselho Nacional de Combate à Discriminação e Promoção dos Direitos de Lésbicas, Gays, Bissexuais, Travestis e Transexuais. Resolução n. 12 de 16 de janeiro de 2015. Estabelece parâmetros para a garantia das condições de acesso e 
permanência de pessoas travestis e transexuais - e todas aquelas que tenham sua identidade de gênero não reconhecida em diferentes espaços sociais [...]. Brasília: Presidência da Republica, 2015. Disponível em:

http://www.lex.com.br/legis_26579652_RESOLUCAO_N_12_DE_16_DE_JANEIRO_DE_2015.a spx. Acesso em: 5 fev. 2020.

BRASIL. Supremo Tribunal Federal. Recurso Extraordinário 845779/SC. Direito administrativo e outras matérias de direito público, garantias constitucionais, não discriminação. Direito civil, responsabilidade civil, indenização por dano moral. Recorrente: André dos Santos Fialho. Recorrido: Beiramar empresa Shopping Center Ltda. Relatora: Min. Roberto Barroso, 22 de outubro de 2014. Disponível em:

http://portal.stf.jus.br/processos/detalhe.asp?incidente=4657292. Acesso em: 6 fev. 2020.

BUTLER, J. Quadros de guerra: quando a vida é passível de luto? Tradução Sérgio Lamarão e Arnaldo da Cunha. Rio de Janeiro: Civilização Brasileira, 2015.

BUTLER, J. Corpos em aliança e a política das ruas. Notas para uma teoria performativa de assembleia. Tradução Fernanda Miguens. Rio de Janeiro: Civilização Brasileira, 2018.

CANGUILLEM, G. O normal e o patológico. Rio de Janeiro: Forense Universitária, 2009.

CARNEIRO, S. Racismo, sexismo e desigualdade no Brasil. São Paulo: Selo Negro, 2011.

CIDH. Corte Interamericana de Direitos Humanos. Opinião Consultiva n ${ }^{\circ}$ 24/2017. Julgado em 24.11.2017. Disponível em: < http://www.corteidh.or.cr/docs/opiniones/ seriea_24_esp.pdf>. Acesso em: 6 fev. 2020.

DINIZ, D. O que é deficiência. São Paulo: Brasiliense, 2007.

FOUCAULT, M. Os Anormais. (Curso no Collège de France, 1974-1975). Tradução Eduardo Brandão. São Paulo: Martins Fontes, 2001.

GAVÉRIO, M. Medo de um planeta aleijado? - Notas para possíveis aleijamentos da sexualidade. Áskesis, v. 4, n. 1, 2015, p. 103-117.

GONÇALVES JÚNIOR, S. W. P. Morte anunciada: reflexões de uma mulher travesti sobre o assassinato de Dandara. In: JESUS, D. M. et al (Orgs.) Corpos transgressores: políticas de resistência. Campinas: São Paulo, 2018, p. 17-21.

GONZALEZ, L. Racismo e sexismo na cultura brasileira. Revista Ciências Sociais Hoje, Anpocs, 1984, p. $223-244$.

MCRUER, R. Compulsory able-bodiedness and queer/disabled existence. In: SNYDER, S.L.;BRUEGGMANN, B.J.;GARLAND-THOMSOM, R. (org.). Disability studies: enabling the humanities. New York: Modern Languague Association of America, 2002. p. 88-99. 
MELLO, A. G. Deficiência, incapacidade e vulnerabilidade: do capacitismo ou a preeminência capacitista e biomédica do Comitê de Ética em Pesquisa da UFSC. Ciênc. saúde coletiva, Rio de Janeiro, 21 (10), 2016, p. 3265-3276.

MELLO, A. G. et al. Entre Pesquisar e Militar: engajamento político e construção da teoria feminista no Brasil. Revista Ártemis. v. 15 n. 1; jan-jul 2013. pp. 10-29. Disponível em: http://www.periodicos.ufpb.br/ojs/index.php/artemis/article/view/16635/9492. Acesso em: 05 dez. 2019

MISKOLCI, R. A teoria queer e a sociologia: o desafio de uma analítica da normalização. Sociologias, Porto Alegre, n. 21, p. 150-182, 2009.

MOIRA, A. O cis pelo trans. Estudos Feministas, Florianópolis, v.25, n.1, p. 365-373, 2017.

NEVES, T. I.; PORCARO, L. A.; CURVO, D. R.Saúde é colocar-se em risco: normatividade vital em Georges Canguilhem. Saúde e sociedade, São Paulo, v.26, n.3, p.626-637, 2017.

ONU - ORGANIZAÇÃO DAS NAÇÕES UNIDAS Conselho de Direitos Humanos. Estudio temático sobre lacuestión de laviolencia contra lasmujeres y lasniñas y ladiscapacidad. 2019.Disponível em: http://www.acnur.org/t3/fileadmin/

Documentos/BDL/2014/9693.pdf?view=1. Acesso em: 10 dez. 2019.

PAMPLONA, P. Mais da metade dos cadeirantes não encontra banheiro acessível. Folha de São Paulo, São Paulo, 23 jul. 2018. Disponível em https://www1.folha.uol.com.br/empreendedorsocial/2018/07/mais-da-metade-doscadeirantes-nao-encontra-banheiro-acessivel.shtml. Acesso em:6 fev. 2020.

RICH, A. Heterossexualidade compulsória e existência lésbica. Tradução Carlos Guilherme do Valle. Bagoas: Estudos gays: gênero e sexualidades, Natal, n. 5, p. 17-44, 2010.

RIO GRANDE DO SUL. Tribunal de Justiça. Apelação Cível 70072252539. Apelação cível. Responsabilidade civil. Ação indenizatória por danos morais. Responsabilidade objetiva do fornecedor. Danos morais in reipsa configurados. Apelante: Clube de baile Gigante do Vale. Relator: Des. Carlos Eduardo Richinitti, 19 de abril de 2017. Disponível em: https://www.conjur.com.br/dl/apelacao-tj-rs-transexual-direito.pdf. Acesso em: 5 fev. 2020.

RIOS, Roger Raupp; RESADORI, Alice Hertzog. Direitos humanos, transexualidade e "direito dos banheiros". Revista Direito e Práxis, v. 6, n. 12, p. 196-227, 2015.

RODRIGUES, G. O. Corpos como objetos abjetos. In: JESUS, D. M. et al (Orgs.) Corpos transgressores: políticas de resistência. Campinas: São Paulo, 2018.

SANTOS, A. L. e SANTOS, A. C. Diversidade funcional, igualdade sexual: sexualidades nãonormativas de mulheres com deficiência. In: SANTOS, A. C. et al. Mulheres, sexualidade, deficiência: os interditos da cidadania íntima. Coimbra: Almedina, 2019.

Recebido em: 31 jul. 2020

Aceite em: 17 set. 2020 